\title{
The World Goes Zoom; Will Restoration Boom?
}

\author{
Steven N. Handel
}

W e sit, in randomly grabbed clothes, staring at a rectangular screen, not a three-dimensional environment, talking to the screen. Our home becomes our private physical world, same walls, same floor, day after day for months. Our friends seem like animations on the screen, bloodless and virtual. Families cannot visit so dinner table settings are thin; lack of restaurant trips also makes us thin. Sports are a memory; instead of waving towels in some athletic arena, we're waving our trowels in the little garden beds in our backyard for excitement. The landscapes we see are mostly the ones out the window, longer trips and excursions just not safe. The great outdoors is a flickering nature video, not experiential. No surprising sounds from around the bend, no smells of nature, no babbling brooks to cross, no muddy boots, no sweat, just a virtual Zoom ecological prison.

We live on Zoom but it's not the life we dream of or we have trained for. Want to get your team together? This becomes a checkerboard of little, little headshots on our screens, positions moving about like electronic whirligigs as people join and leave, then join again. We want to see our friends or coworkers, but everyone has a mask on and looks like a cloned batch of blue-faced robots. We want to go to the plant nursery again, but is it safe? We want to go work in the field, but how can we do this six feet apart from the folks we rely on to share the work?

Zoom sounds so fast, but our lifestyle has so slowed down. Online, we say something clever or something smart, but we were muted, and nobody heard it. Talk louder they say, but there's a kid sleeping in the next room and you can't. Internet goes down and the day "at work" is lost for hours.

Lonely. So lonely. We're supposed to be a social species. But Zoom makes us as lonely as that proverbial cloud, wondering where disease will blow us next. Let's have a party! But that just means more little rectangular portraits on the flatscreen social space. When will it end? So many

Ecological Restoration Vol. 39, Nos. 1-2, 2021

ISSN 1522-4740 E-ISSN 1543-4079

(O2021 by the Board of Regents of the University of Wisconsin System. friends are still alive, so we can't complain. We just can't complain. But when will it end?

Ecological restoration is an optimistic field, charged with improving our physical landscape which drives all those nature services we brag about. Is this disease only casting shadows on our lives, or can there be some good that comes of it? Can there be a boom in our restoration work now? Let's make a list.

Almost no commuting now. Less carbon emitted to the air, a break in the relentless march of climate change. About 75\% fewer international arrivals occurred in 2020 compared to previous years. This is an enormous advantage for a degrading stratosphere. Less time on the road means more time for families, local walking, more plans for pleasurable pursuits instead of waiting for that line of honking traffic to clear. Working at home on our Zoom platforms has driven a reconsideration of why the heck did we need to go into the office at all, most days.

City streets are quieter as commercial real estate is emptying; much of it may go extinct like a high-rise stegosaurus. Less need for parking spaces. Urban planners have not ignored all this. Maybe many city streets, post-covid, can be pedestrianized. With some commercial office space not needed as work rules change, at-risk buildings in coastal flooding zones might be abandoned. The new available space could be assigned for other urban activities such as open space or community-supported agriculture, difficult to financially justify with the previous real estate valuation models. Flooding damage retreats even as the tides rise.

Those lines of parking spaces can be replaced by urban green corridors and bioswales. Perhaps our city parks can be better connected with a streetscape of green space, allowing movement of seeds and animals, shading the new pedestrians, and cleaning the air they breathe. The greener streets help mitigate heat stress in our ever-heating world. A Zoom technology may quickly lead to birds and butterflies zooming down our now quiet city streets. This a real advantage in the newly virtual world. Lack of social interactions, as we avoid our possibly contaminated neighbors, may lead to a richer biodiversity around us in our quieter urban centers. Years of lobbying for biotic links among green spaces may become successful as the calculus of sharing space among nature, parking, and crowded 
commercial streets gets recomputed. Already there are reports of more wildlife in our urban centers, whether it's rabbits in Calgary or coyotes in Los Angeles. This may not be everybody's cup of tea, but it's a long-awaited drink for those of us who wish a natural experience as part of city life.

As space for cars and commercial needs thin in the Zoomed world, this means more room for urban agriculture initiatives, building nutrition and food security for underserved populations. Remote work may indirectly lead to more environmental justice as the political stresses of needing space for yuppie domiciles and 9-to-5 parking lots for those harried commuters lessens.

Our native plant nursery owners are marveling at how many plants they are selling as more people turn to home gardening to keep sane, if not to increase food plants for Lepidoptera caterpillars. For so many people, a day in the garden has replaced a night at the cinema. We know that ecological restoration has gained advocates in the last few decades, but the switch to Zoom-centered work patterns has added local, home-based restoration actions to match the movement's goals. In the world of the plague, new habits apparently include planting new habitats.

There is a dark side to the Zoom force also, alas. So much of restoration work requires teams of people working closely together. The contractors or volunteers do the work, collecting seed, or restoring diversity in the local meadow. Commercial companies contracted to do restoration work must marry public health rules and needs with the timing and staff budgets that they must craft to turn a profit. The Zoom world doesn't help with these needs; Zoom, in a twist, slows these down too.

With the obvious necessity of funds going for public health, food pantries, and social work support for families in the grip of urgent needs, there is less charity and time to think about local restoration actions and their financial requirements. We have always had a triage for charitable giving. The mounting sickness and death toll around us has lowered the attention for overall environmental progress, at least for now.

The year 2020 has been one that even a great science fiction writer could not have crafted. An invisible microbe has overpowered the major military and economic powers of our modern world. Mother Nature rules, even when part of Mother Nature is a deadly disease. We are humbled, biology rules. Zoom is the partner we face each working day, but outside that window we face the ecological realities which run our world. 